\title{
New insights into the stability of alkenes and alkynes, fluoro-substituted or not: a DFT, G4, QTAIM and GVB study
}

\author{
Gutto Raffyson Silva de Freitas • Caio Lima Firme
}

Received: 2 May 2013 / Accepted: 23 September 2013 / Published online: 17 October 2013

(C) Springer-Verlag Berlin Heidelberg 2013

\begin{abstract}
Many undergraduate organic chemistry books do not agree with the order of relative stability of alkenes towards hydrogenation reactions. Although they ascribe the stability of alkenes to the number and spatial position of the alkyl groups attached to the vinyl carbon atoms, results from the quantum theory of atoms in molecules indicate that the influence of an alkyl substituent on the stability of unsaturated hydrocarbons arises from the slight removal of electron density of the $\pi$ bond, not from donation of their charge density to unsaturated carbon atoms as stated in many text books. There is an inverse relation between delocalization index - the number of shared electrons between two atoms, or Wiberg bond index of $\mathrm{C}=\mathrm{C}$ bond - and the number of methyl groups attached to the vinyl carbon atoms. Electron withdrawing groups (EWGs) attached to unsaturated carbon atoms of alkenes and alkynes have two different behaviors: slight EWGs (alkyl groups) stabilize unsaturated carbon atoms while the strong EWG destabilizes the unsaturated carbon atoms. Generalized valence bond theory was also used to study the ambiguous behavior of fluorine substituents bonded to vinyl carbon atoms.
\end{abstract}

Keywords QTAIM · DFT · GVB · Alkene · Alkyne · Stability

\section{Introduction}

The first calorimetric measurements of unsaturated compounds were not very precise. In order to improve their precision,

G. R. Silva de Freitas $•$ C. L. Firme $(\bowtie)$

Institute of Chemistry, Federal University of Rio Grande do Norte,

Av. Salgado Filho, s/n, Lagoa Nova, Natal,

RN CEP 59000-000, Brazil

e-mail: firme.caio@gmail.com

C. L. Firme

e-mail: caiofirme@quimica.ufrn.br
Kistiakowsky and coworkers [1-7] measured the heat of hydrogenation of several unsaturated organic compounds in gas phase through catalytic hydrogenation, with a degree of uncertainty of $\pm 0.20 \%$. However, this technique could be applied only to appreciably volatile substances. Later, Williams proposed an extension of Kistiakowsky and coworkers' method to the condensed phase, making it possible to obtain heats of hydrogenation of other unsaturated compounds [8]. Following Kistiakowsky's work, several hydrogenation calorimetric measurements with different solvents arose [9-11].

Alternatively, Rossini and coworkers [12] determined the heat of combustion of a series of hydrocarbons in gas phase, and also analyzed the effect of methylene addition in the hydrocarbon heat of combustion.

The heat of hydrogenation is one of the thermodynamic criteria most often used to evaluate the relative stability of alkenes and alkynes [13]. The heat of hydrogenation is restricted to the stability of the $\pi$ bond present in the molecule rather than that of the whole molecule [14]. On the other hand, the heat of combustion can be used to evaluate the overall stability of the hydrocarbon, and allows better comparison among alkenes with different degrees of substitution since the products of the combustion reaction are always the same (water and carbon dioxide) [15]. However, the heat of combustion cannot be used to compare reaction energy difference values for substituted alkenes with those of non-hydrocarbon substituent groups.

Although experimental heats of hydrogenation and/or combustion have been obtained for many organic compounds, these data are not available for all hydrocarbons due to incomplete reaction, side reaction and lack of accuracy. This being the case, one way to address this problem is to use theoretical empirical methods. Early empirical methods were not successful for many different reasons [16]; however, by employing the parameterized additive method of group contributions, Sagadeev and Barabanov [16] calculated the enthalpies of combustion of 
more than 200 organic compounds (hydrocarbons, alcohols, aldehydes, etc.) with $1 \%$ error in comparison with experimental results.

In the 1980s, ab initio calculations performed by Schleyer and Ibrahim [17], Dewar and Storch [18] and Wiberg [19] determined the formation enthalpies in gas phase for some restricted classes of compounds. The drawbacks of these early ab initio studies were computing limitations and inaccuracies of correlation energy. The method of rapid estimation of basis set error and correlation from partial charges (RECEP), developed by Csonka et al. [20-23] was used to calculate the enthalpies of formation of dozens of organic compounds. By performing parametrizations on B3LYP, Cioslowski et al. [24-26] applied the bond density function approach to calculate formation enthalpies with an average absolute error of $3.3 \mathrm{kcal} \mathrm{mol}^{-1}$.

Whyman and co-workers performed ab initio calculations to obtain formation and combustion enthalpies of several saturated and unsaturated, cyclic and aliphatic hydrocarbons. They observed a two-fold decrease of errors when going from a linear chain to a strained cyclic structure, which they ascribed to free rotation of fragments in the linear structure [27].

The undergraduate organic chemistry textbooks cited here $[15,28-30]$ ascribe the stability of alkenes to the number and spatial position of alkyl groups attached to the vinyl carbon atoms [31]. The stability of alkenes is related directly to the number of alkyl groups bonded to their vinyl carbon atoms (see Scheme 1 where selected relative stability orders of alkenes were taken from some undergraduate books). Literature shows that the heats of hydrogenation of most alkenes are nearly $-30 \mathrm{kcal} \mathrm{mol}^{-1}$.

From Scheme 1, we note that the order of relative stability of alkenes towards hydrogenation reactions is not the same for all references. Similar observations can be made from the work of Cunha [31].

From ab initio calculations, Whangbo and Stewart [32] found that HOMO energy of alkenes increases and $\pi$ bond energy decreases as the number of alkyl groups attached at

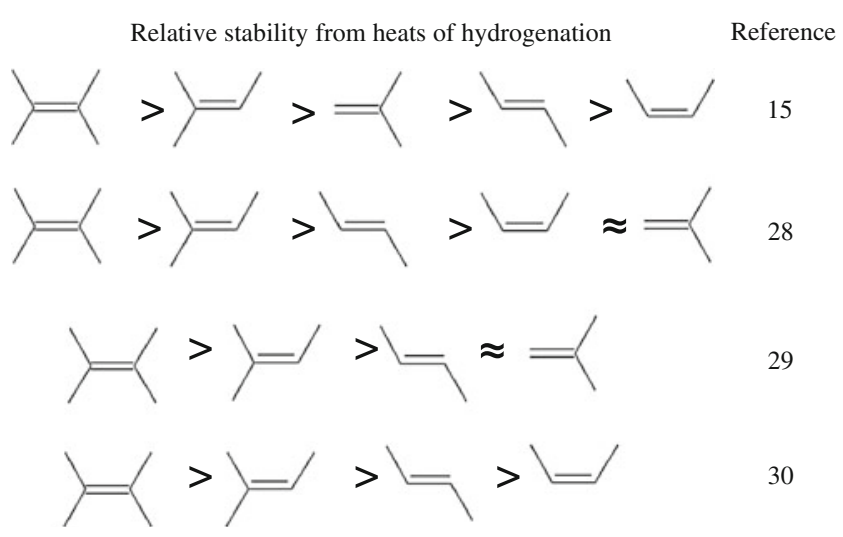

Scheme 1 Relative stability of alkenes towards hydrogenation reaction from calorimetric measures according to $15,28,29$ and 30
$\mathrm{C}\left(\mathrm{sp}^{2}\right)$ increases. Schleyer and Kost [33], Schmidt et al. [34] and Sun et al. [35] used ab initio methods to calculate the strength and energy of the $\pi$ bond from several unsaturated molecules, including compounds with heteroatoms bonded by double bond to vinyl carbon.

The n-Gaussian methods ( $n=1,2,3$ and 4$)$ arose from the observation that some ab initio methods have a systematic error in the energy calculation of some important molecular systems. These n-Gaussian models (Gn) employ an array of well-defined ab initio calculations in order to obtain accurate thermochemical data [36]. Each generation has a distinct array. The fourth generation of the n-Gaussian method, G4, came up with significant improvements in comparison with $\mathrm{G} 3$, in the determination of formation enthalpies, proton and electron affinities. G4 modifies $\mathrm{G} 3$ by adding an extrapolation procedure to obtain a Hartree-Fock (HF) limit in the total energy calculation; increasing $d$-polarization sets to $3 \mathrm{~d}$ on first-row atoms and $4 \mathrm{~d}$ on second-row atoms; replacing QSCISD(T) by CCSD(T) for the highest level of correlation treatment; and using B3LYP for geometry optimization and zero point calculations [37].

In this work, we used quantum theory of atoms in molecules (QTAIM), density functional theory (DFT) and the G4 method to study the topology and stability of alkenes and alkynes, fluoro-substituted or not, by means of their electron densities and thermodynamics of combustion and hydrogenation reactions, respectively. We also used different kinds of electron withdrawing groups (EWGs) attached to vinyl carbons $\left[\mathrm{C}\left(\mathrm{sp}^{2}\right)\right]$ and acetylenic carbon $[\mathrm{C}(\mathrm{sp})]$ atoms to evaluate their influence on the stability of corresponding alkenes and alkynes, respectively. In addition, generalized valence bond (GVB) calculations from VB2000 method [38] for fluorinesubstituted alkenes were performed to evaluate the ambiguous behavior of fluorine substituent. Unlike statements taken from undergraduate organic chemistry textbooks, QTAIM results, along with Wiberg bond index values, indicate that the influence of alkyl substituents on the stability of unsaturated hydrocarbons arises from the slight removal of electron density from the $\pi$ bond and not from a charge density donation of the alkyl group.

\section{Computational details}

The geometries of the studied species were optimized according to Berny's algorithm using energy-represented direct inversion in the iterative subspace (DIIS) in redundant internal coordinates [39, 40]. Vibrational analysis on the optimized geometries of selected points of the potential energy surface (PES) was carried out in order to determine whether the resulting geometries are true minima or transition states, by checking the existence of imaginary frequencies. The calculations were performed at B3LYP/6-311++G(d,p) level 
$[41,42]$ and G4 [37] levels of theory by using Gaussian 09 package [43]. Search for the lowest minimum at PES was done by conformational analysis of alkenes with alkyl groups as substituents.

The values of free energy of combustion were parameterized to allow comparison among them since the stoichiometric coefficients of reactants and products of each combustion reaction are not the same for all reactions. A parameter each from the combustion reactions of ethene and ethyne was chosen. Based on the stoichiometry of these reactions, the values of parametrized free energy of combustion were obtained using the relation: $2 \Delta \mathrm{G}_{\text {comb }} / \mathrm{x}$, where $\mathrm{x}$ is the stoichiometric coefficient of the $\mathrm{CO}_{2}$ molecule of each combustion reaction. Then, except for the combustion reactions of ethene and ethyne, all other values of free energy of combustion reaction were parameterized. As stated above, one disadvantage when using combustion reaction as a stability parameter for alkenes and alkynes is that the values of free energy of the combustion reaction of unsaturated compounds containing fluorine atoms cannot be parameterized to be comparable with the corresponding values of $\Delta \mathrm{G}_{\mathrm{comb}}$ of ethyne and ethene or other alkynes and alkenes. In addition, there is a smaller energy difference in the calculated combustion reaction in comparison with the calculated hydrogenation reaction, which gives less precision to the former.

Electronic density was derived from Kohn-Sham orbitals and further used for QTAIM calculations by means of AIM2000 software [44]. The algorithm of AIM2000 for searching critical points is based on the Newton-Raphson method, which relies heavily on the chosen starting point [45]. Iterations to find critical points begin with nuclear positions, mean values of maxima pairs and mean values of maxima triples, followed by iterations from grid points at a chosen start point nearby a possible critical point. The delocalization index (DI), obtained from the integration of the Fermi hole density, is a measure of the number of electrons that are shared or exchanged between two atoms or basins [46]. Because the source of correlation at the HF level is the Fermi correlation, changes in DIs when going from an HF to a correlated wave function, i.e.,, after the inclusion of Coulomb correlation, are expected to be small [47].

Usually, DIs have a minor dependence on the basis set [48, 49]. The values of DI obtained from DFT are expected to be more reliable than those from the HF method [50], since DFT one-electron density describes a partial contribution of electron correlation. However, because the DIs are derived from an approximate monodeterminantal wave function, this index is often overestimated $[47,51]$. However, for the purposes of comparison, this overestimation should not affect the trends or correlations involving DIs found in this work.

The DI, along with other topological and non-topological data, has been used to establish whether the analyzed substituent group attached to vinyl or acetylenic carbon is an EWG or an electron donating group relative to a reference molecule (ethylene or acetylene for alkenes or alkynes, respectively). In addition, it is important to emphasize that the DI is not a measure of bond strength, although it is correlated with bond order [52].

Other topological descriptors (AIM atomic charge, charge density and Laplacian of the charge density in the bond critical point) were also used to corroborate DI results. The AIM atomic charge is obtained from the integration of electron density within the corresponding atomic basin and the Laplacian of the charge density is the sum of the three eigenvalues of the Hessian matrix of the charge density $\left(\lambda_{1}, \lambda_{2}\right.$, and $\left.\lambda_{3}\right)$. A negative sign for $\nabla^{2} \rho$ represents the concentration of the charge density while a positive sign for $\nabla^{2} \rho$ represents charge depletion.

Another important analysis from the QTAIM theory is the ellipticity $(\varepsilon)$, which is given by $\left(\lambda_{1} / \lambda_{2}\right)-1$, where $\lambda_{1}$ and $\lambda_{2}$ are eigenvalues of the Hessian matrix of the charge density; $\varepsilon$ is a measure of how the electron density distribution is distorted from the axial symmetry of the bond.

The Wiberg bond index [53] provides insight into the nature of the bond and could be used to interpret changes in electronic structures when changing the substituent. In this work, the Wiberg bond index was used to compare the DI of alkene and alkynes, fluoro-substituted or not.

Valence bond calculations were performed at GVB/6-31++ $G(d, p)$ level of theory by means of VB2000 software [54]. GVB orbitals were generated in the Molekel visualization program [55]. In order to evaluate the ambiguous behavior of fluorine atom in fluoroethene, we performed GVB calculations based on group function theory (GFT). The generalized valence bond [56] method generates one VB structure for a given number of valence electrons and orbitals by means of perfect-pairing approximation, where its wave function is a product of germinal two-electron functions that are associated with a particular bond or lone pair. The GFT method [38] is used for all valence bond methods in VB2000 and divides the molecule in two parts: HF localized orbitals and VB orbitals, yielding a CASSCF-type wavefunction with univocal VB orbitals.

\section{Results and discussion}

The alkenes studied in this work ranged from ethylene (only hydrogen atoms bonded to vinyl carbon atoms) to 2,3-dimethyl-2-butene (only methyl groups bonded to vinyl carbon atoms). Fluorine substituents bonded to vinyl or acetylenic carbon atoms, respectively, were also used to better understand the stability of alkenes and alkynes and their corresponding topological properties. It is important to note that stability is a thermodynamic property that does not depend on the mechanism of the reaction being considered. 
The free energy of combustion of alkenes and alkynes was calculated. However, for the purposes of comparison, it could not be applied to substituted alkenes and alkynes (with fluorine substituents). For a more comprehensive evaluation involving substituted and not substituted alkenes and alkynes, heat and free energy of hydrogenation were then calculated and used for comparative analysis with topological and nontopological data. The former could be compared directly with experimental data and the latter encompasses both enthalpy and entropy contributions in the study of the thermodynamic behavior of hydrogenation reactions.

Table 1 shows the free energy of hydrogenation $\left(\Delta \mathrm{G}_{\text {hyd }}\right)$ of studied alkynes and alkenes, fluoro-substituted or not, from B3LYP/6-311++G(d,p) and G4 levels of theory, the free energy of combustion and enthalpy of hydrogenation at the G4 level of theory, plus the $\mathrm{DI}$ of $\mathrm{C}=\mathrm{C}$ or $\mathrm{C} \equiv \mathrm{C}$ bonds, Wiberg bond index of $\mathrm{C}=\mathrm{C}$ or $\mathrm{C} \equiv \mathrm{C}$ bonds, the $\mathrm{AIM}$ atomic charge of carbon atom $[\mathrm{q}(\mathrm{C})]$ of vinyl or acetylenic carbon from B3LYP electron density and bond lengths of double and triple $\mathrm{CC}$ bonds.

The heat of hydrogenation and free energy of hydrogenation, calculated by G4 level of theory, have the same order of stability except for a slight inversion (derived from a small energy difference) between 2-methyl-2-butene and 2,3-dimethyl-2-butene, which could indicate that 2-methyl-2-butene tends to be more stable than 2,3-dimethyl-2-butene when the entropy contribution is not considered. Alternatively, 2,3-dimethyl-2-butene is slightly more stable than 2-methyl-2-butene when comparing free energy of combustion (from B3LYP/6-311G++** level of theory) and free energy of hydrogenation (from both B3LYP/6-311G++** and G4). This inversion indicates an imprecise order of stability between 2methyl-2-butene and 2,3-dimethyl-2-butene. A possible reason for the difference in the order of stability involving 2methyl-2-butene and 2,3-dimethyl-2-butene could be the competition between stabilizing inductive effect and the destabilizing steric hindrance effect of methyl substituents bonded to vinyl carbon atoms.

Owing to the fact that all studied reactions are exergonic (Table 1), the stability of the unsaturated molecule (the reactant in all studied reactions) increases as $\Delta \mathrm{G}_{\text {hyd }}$ becomes less exergonic. We use this assumption to derive all orders of stability presented in this work.

Scheme 2 shows the order of relative stability, with respect to their $\pi$ bonds, of the free energy of hydrogenation of selected non-substituted alkenes obtained from Table 1. The related orders of stability from Scheme 2 are in agreement with the well-known statement that the stability of unsaturated hydrocarbons increases as the number of alkyl groups bonded to vinyl carbon atoms increase for alkenes. This order of stability is similar for both levels of theory used in this work. We found the same order of stability as in Scheme 2 in Allinger's Organic Chemistry [57]. No order of stability of alkenes in Scheme 1 is similar to that calculated in this work, although those from references [15] and [30] are closest to that in Scheme 2.

The analysis of AIM atomic charge and DI in Table 1 indicate that, as the number of alkyl groups attached to vinyl or acetylenic carbon atom increases, the charge density in the bonding region of $\mathrm{C}=\mathrm{C}$ or $\mathrm{C} \equiv \mathrm{C}$ bond and the charge density in the atomic basins involved in these bonds decrease (or becomes less negative in the case of atomic charge), when compared to ethene and ethyne, respectively. Even one aryl group attached to vinyl or acetylenic carbon atom decreases the charge density in the bonding region and in the carbon atomic basin of double and triple $\mathrm{CC}$ bonds, when compared to ethene or ethyne.

Table 2 shows the charge densities $(\rho)$, Laplacians of the charge density $\left(\nabla^{2} \rho\right)$ and ellipticities $(\varepsilon)$ of the bond critical points (BCPs) of studied alkynes and alkenes, fluorosubstituted or not, from B3LYP electron density.

Analyzing charge densities and Laplacian of the charge density of $\mathrm{C}=\mathrm{C}$ and $\mathrm{C} \equiv \mathrm{C}$ BCPs (Table 2), it is possible to observe a decrease in charge density of the $\pi$ bond when the number of alkyl groups attached to the unsaturated carbon atom increases. This trend is in accordance with that found for the DI. Accordingly, the Laplacian of the charge density becomes less negative, i.e., the charge density of the $\mathrm{C}=\mathrm{C}$ and $\mathrm{C} \equiv \mathrm{C}$ bonds become less concentrated, as the number of alkyl groups attached to the unsaturated carbon atom increases.

The ellipticity values for alkynes are very close to zero, indicating that the distribution of electron density at the triple bond is very symmetrical, while no cylindric symmetry is found in double $\mathrm{CC}$ bonds, as expected. In the case of alkenes, the value of $\varepsilon$ increases as the number of alkyl groups or fluorine atoms attached to vinyl carbon atoms increases (see Table 2), yielding a more distorted electron distribution along the $\mathrm{C}=\mathrm{C}$ bond.

Values of DI, AIM atomic charge and charge density of $\mathrm{BCP}$ indicate that alkyl and aryl groups when attached to $\mathrm{C}=\mathrm{C}$ or $\mathrm{C} \equiv \mathrm{C}$ bonds are not electron donating groups as stated in the current literature but EWGs.

One may assume that when decreasing the charge density in the bonding region the corresponding bond length tends to increase. Accordingly, the variation in bond length of double and triple $\mathrm{CC}$ increases when the number of alkyl groups attached to vinyl or acetylenic carbon increases because the charge density in the bonding region of these $\pi$ bonds decreases. Then, bond length values in Table 1 follow the expected trend in accordance with the variation of AIM atomic charge, charge density of BCP and DI. As a consequence, the alkyl groups and aryl group in alkene and alkyne behave as slight EWGs, where the slight decrease of charge density of the $\pi$ bond region leads to an increase in their stabilities. 
Table 1 Free energy of hydrogenation $\left(\Delta \mathrm{G}_{\mathrm{hyd}}\right)$, in $\mathrm{kcal} \mathrm{mol}^{-1}$, of studied alkynes and alkenes, fluoro-substituted or not, from B3LYP/6-311++G(d, p) and G4 levels of theory, parametrized free energy of combustion $\left(\Delta \mathrm{G}^{\prime}{ }_{\text {comb }}\right)$, in $\mathrm{kcal} \mathrm{mol}{ }^{-1}$, from B3LYP/6-311++G(d,p), enthalpy of hydrogenation from $\mathrm{G} 4$, delocalization index of $\mathrm{C}=\mathrm{C}$ or $\mathrm{C} \equiv \mathrm{C}$ bonds
[DI(CC)], Wiberg bond index of $\mathrm{C}=\mathrm{C}$ or $\mathrm{C} \equiv \mathrm{C}$ bonds, atomic charge of carbon atom $[q(\mathrm{C})]$ of vinyl or acetylenic carbon, in a.u., from B3LYP electron density, and $\mathrm{C}=\mathrm{C}$ or $\mathrm{C} \equiv \mathrm{C}$ bond lengths, in Angstroms, from B3LYP/6-311++G(d,p) and G4 levels of theory. AIM Atoms in molecules

\begin{tabular}{|c|c|c|c|c|c|c|c|c|c|}
\hline \multirow[t]{2}{*}{ Molecule } & \multirow{2}{*}{$\begin{array}{l}\Delta \mathrm{G}_{\text {comb }}{ }^{\mathrm{a}} \\
(\mathrm{kcal} / \mathrm{mol}) \\
\text { B3LYP }\end{array}$} & \multicolumn{2}{|c|}{$\Delta \mathrm{G}_{\mathrm{hyd}} / \mathrm{kcal} \mathrm{mol}^{-1}$} & \multirow{2}{*}{$\begin{array}{l}\Delta \mathrm{H}_{\mathrm{hyd}} / \mathrm{kcal} \mathrm{mol}^{-1} \\
\mathrm{G} 4\end{array}$} & \multirow{2}{*}{$\begin{array}{l}\text { DI } \\
\text { (CC) }\end{array}$} & \multirow[t]{2}{*}{ Wiberg bond index } & \multirow{2}{*}{$\begin{array}{l}\text { AIM properties } \\
\text { (B3LYP) } \\
\text { q (C)/a.u. }\end{array}$} & \multicolumn{2}{|c|}{$\mathrm{CC}$ bond length $/ \AA$} \\
\hline & & B3LYP & G4 & & & & & B3LYP & G4 \\
\hline \multicolumn{10}{|l|}{ Alkenes } \\
\hline Ethene & -298.27 & -23.91 & -24.05 & -32.48 & 1.90 & 2.04 & -0.043 & 1.328 & 1.327 \\
\hline Propene & -293.28 & -19.80 & -20.77 & -29.31 & 1.84 & 1.97 & $-0.058 /-0.021^{\mathrm{c}}$ & 1.331 & 1.329 \\
\hline trans-butene & -291.54 & -17.04 & -18.74 & -27.04 & 1.79 & 1.92 & -0.035 & 1.332 & 1.331 \\
\hline cis-Butene & -292.04 & -18.04 & -19.79 & -28.35 & 1.79 & 1.92 & -0.033 & 1.336 & 1.333 \\
\hline 2-Methylpropene & -291.17 & -16.99 & -18.75 & -27.53 & 1.79 & 1.90 & $-0.065 /-0.015^{\mathrm{d}}$ & 1.334 & 1.332 \\
\hline 2-Methyl-2-butene & -290.77 & -14.72 & -17.39 & -26.42 & 1.75 & 1.85 & $-0.038 /-0.022^{\mathrm{d}}$ & 1.339 & 1.337 \\
\hline 2,3-Dimethyl-2-butene & -291.68 & -12.23 & -16.71 & -26.81 & 1.72 & 1.80 & -0.032 & 1.346 & 1.344 \\
\hline Fluoroethene & $-{ }^{b}$ & -21.76 & -22.26 & -30.71 & 1.80 & 1.96 & $0.001 / 0.444^{\mathrm{e}}$ & 1.320 & 1.321 \\
\hline 1,2-Difluoroethene & $-{ }^{\mathrm{b}}$ & -23.92 & -24.06 & -33.00 & 1.69 & 1.87 & 0.528 & 1.323 & 1.324 \\
\hline 1,1,2-Trifluoroethene & $-^{\mathrm{b}}$ & -29.17 & -30.68 & -39.20 & 1.60 & 1.80 & $0.631^{\mathrm{e}} / 1.071^{\mathrm{f}}$ & 1.322 & 1.324 \\
\hline Tetrafluoroethene & $-{ }^{\mathrm{b}}$ & -39.18 & -41.45 & -49.65 & 1.55 & 1.73 & 1.168 & 1.322 & 1.323 \\
\hline Styrene & -246.42 & -17.96 & -19.72 & -28.22 & 1.77 & 1.90 & $-0.040 /-0.005^{\mathrm{g}}$ & 1.336 & 1.334 \\
\hline \multicolumn{10}{|l|}{ Alkynes } \\
\hline Ethyne & -283.27 & -59.46 & -58.27 & -73.88 & 2.71 & 2.99 & -0.080 & 1.199 & 1.198 \\
\hline Ethynylbenzene & -241.60 & -49.23 & -51.54 & -68.47 & 2.51 & 2.82 & $-0.044 /-0.059^{\mathrm{g}}$ & 1.205 & 1.204 \\
\hline 2-Buthyne & -279.84 & -44.19 & $\mathrm{~h}_{-}$ & $\mathrm{h}$ & 2.52 & 2.77 & -0.094 & 1.204 & $-\mathrm{h}$ \\
\hline Propyne & -280.43 & -51.08 & -51.79 & -68.43 & 2.64 & 2.87 & $-0.072 /-0.134^{\mathrm{c}}$ & 1.202 & 1.201 \\
\hline Fluoroethyne & $-^{\mathrm{b}}$ & -73.84 & -73.66 & -89.76 & 2.62 & 2.83 & $0.205 / 0.254^{\mathrm{e}}$ & 1.193 & 1.193 \\
\hline Difluoroethyne & $-^{\mathrm{b}}$ & -91.08 & -91.55 & -108.08 & 2.47 & 2.71 & 0.655 & 1.184 & 1.184 \\
\hline
\end{tabular}

${ }^{a}$ Values of parametrized free energy of combustion were obtained by using the relation: $2 \Delta \mathrm{G}_{\text {comb }} / \mathrm{x}$, where $\mathrm{x}$ is the number of $\mathrm{CO}_{2}$ yielded in the combustion reaction. The parameter is based on combustion reaction of ethane (for alkenes) and of ethyne (for alkynes)

${ }^{\mathrm{b}}$ The corresponding $\Delta \mathrm{G}_{\text {comb }}$ of these compounds values cannot be parametrized to be comparable with the corresponding values of $\Delta \mathrm{G}_{\mathrm{comb}}$ of ethyne and ethene because of the presence of heteroatom $\mathrm{F}$

${ }^{\mathrm{c}}$ Carbon bonded to methyl substituent

${ }^{\mathrm{d}}$ Carbon bonded to two methyl substituents

${ }^{\mathrm{e}}$ Carbon bonded to one fluorine atom

${ }^{\mathrm{f}}$ Carbon bonded to two fluorine atoms

${ }^{\mathrm{g}}$ Carbon bonded to phenyl

${ }^{\mathrm{h}}$ No minimum in the PES was found for 2-buthyne by using G4 level of theory

The value of $\mathrm{DI}$ of $\mathrm{C}=\mathrm{C}$ bond in cis/trans-butene and 2methyl propene is the same $(\mathrm{DI}=1.79)$ although they have different relative stabilities. Likewise, their corresponding Wiberg bond index values are also very similar (1.92 and 1.90). These DI and Wiberg index results are reasonable because cis/trans-butene and 2-methyl propene have the same number of alkyl groups attached to the vinyl carbon where they contribute equally to the number of shared electrons in $\mathrm{C}=\mathrm{C}$ bond. Moreover, the influence of substituent group in DI and Wiberg bond index of a vicinal bond occurs only by electron donation or removal (from inductive effect, hyperconjugation or resonance effect), and it does not occur<smiles>C=C/C=C/C=C(C)/C=C/C=C/C=C/C</smiles>

Scheme 2 Relative stability obtained from free energy of hydrogenation reaction of alkenes according to B3LYP/6-311++G(d,p) and G4 levels of theory 
Table 2 Charge densities $(\rho)$, Laplacians of the charge density $\left(\nabla^{2} \rho\right)$ and ellipticities $(\varepsilon)$ of the bond critical points (BCPs) of studied alkynes and alkenes, fluoro-substituted or not, from B3LYP electron density

\begin{tabular}{llll}
\hline Molecule & $\rho(\mathrm{au})$ & $\nabla^{2} \rho(\mathrm{au})$ & $\varepsilon$ \\
\hline Alkenes & & & \\
$\quad$ Ethene & 0.344 & -1.029 & 0.330 \\
$\quad$ Propene & 0.343 & -1.016 & 0.350 \\
Trans-butene & 0.342 & -1.005 & 0.371 \\
Cis-butene & 0.339 & -0.987 & 0.372 \\
2-Methylpropene & 0.341 & -1.000 & 0.365 \\
2-Methyl-2-butene & 0.337 & -0.969 & 0.389 \\
2,3-Dimethyl-2-butene & 0.331 & -0.927 & 0.409 \\
Fluoroethene & 0.352 & -1.074 & 0.419 \\
1,2-Difluoroethene & 0.354 & -1.084 & 0.578 \\
1,1,2-Trifluoroethene & 0.351 & -1.053 & 0.738 \\
Tetrafluoroethene & 0.351 & -1.020 & 0.932 \\
Styrene & 0.339 & -1.002 & 0.324 \\
Alkynes & & & \\
Ethyne & 0.412 & -1.241 & 0 \\
Ethynylbenzene & 0.406 & -1.200 & 0.023 \\
2-Buthyne & 0.403 & -1.156 & 0 \\
Propyne & 0.407 & -1.195 & 0 \\
Fluoroethyne & 0.393 & -0.886 & 0 \\
Difluoroethyne & 0.387 & -0.851 & 0 \\
\hline
\end{tabular}

by van der Waals forces derived from intramolecular repulsions between these substituents as in the case of cis-butene.

Figure 1 shows the increasing order of stability, according to hydrogenation reaction, relative to their $\pi$ bonds, of alkenes and alkynes, fluoro-substituted or not, from B3LYP/6-311++ $\mathrm{G}(\mathrm{d}, \mathrm{p})$ and G4 levels of theory. No difference between both calculations exists for the order of stability of all alkynes, substituted and not, except for the absence of 2-butyne optimized structure from $\mathrm{G} 4$.

According to the atomic charge of vinyl carbon, only a slight removal of the charge density occurs because this atom becomes slightly less negative as the number of alkyl substituents attached to the vinyl carbon atom goes from zero (ethene, -0.043 au.), one (propene, $-0.021 \mathrm{au}$.), and two (2-methylpropene, $-0.015 \mathrm{au}$.). As a consequence, the alkyl groups are slight EWGs in alkynes and alkenes.

Therefore, when attached to unsaturated carbon atoms of alkene or alkyne, alkyl groups are not electron donating groups as stated by organic chemistry textbooks. However, they do stabilize the unsaturated $\mathrm{CC}$ bond with respect to a reference molecule (ethene or ethyne). It is important to emphasize that alkyl substituents behave differently (as electron donating groups) when attached to trivalent carbon atoms in carbocation intermediates.

The dual behavior of alkyl group is a consequence of the fact that it is neither a strong EWG nor a strong electron donating group. Its behavior will then be dependent on the electron density environment to which it is attached. In a poor electron density environment, such as a sigma intermediate or carbocation intermediate, the alkyl group is a moderate electron donating group, while in a rich electron density environment, such as in ethene or ethyne, the alkyl group is a moderate EWG.

Regarding the free energy of hydrogenation for all studied alkenes, fluoro-substituted or not, we can see that two fluorine atoms attached to the same vinyl carbon atom decrease the stability of the substituted alkene with respect to ethene and ethyne, respectively (Fig. 1). Nonetheless, when only one fluorine atom is attached to each vinyl carbon atom, a different behavior towards stability of $\pi$ bond occurs: fluoroethene and 1,2-difluoroethene have greater or similar stability with respect to ethene, respectively. The DI and Wiberg bond index of $\mathrm{C}=\mathrm{C}$ bond in fluorethene is higher than that from trans/cisbutene or other alkenes with higher number of alkyl substituents. Even in 1,2-difluoroethene, the difference of its $C=C$ DI and Wiberg bond index is less significant when comparing to that from 2,3-dimethyl-2-butene. Nonetheless, two fluorine atoms bonded to the same vinyl carbon atom leads to a more prominent decrease in $\mathrm{C}=\mathrm{C}$ DI and Wiberg bond index.

In accordance with the stability trend shown in Scheme 2, the DI and Wiberg bond index results in Table 1 also reveal the ambiguous nature of fluorine substituent in alkenes. Thus, in the case of substituted alkenes, a fluorine substituent can be regarded as a strong EWG only when two fluorine atoms are attached to only one vinyl carbon atom (in 1,1,2-trifluoroethene) or attached to both carbon atoms (in tetrafluoroethene).

One fluorine atom bonded to each vinyl carbon atom behaves as a slight EWG, which stabilizes the unsaturated hydrocarbon by slight removal of the charge density from the corresponding $\pi$ bond. This slight removal occurs because one fluorine atom is not such a strong EWG according to its Hammett substituent constants $\left(\sigma_{\mathrm{p}}=0.06, \sigma^{+}=-0.07 ; \sigma^{-}=\right.$ $\left.-0.03 ; \sigma_{R}=-0.48\right)$, which can be attributed to its opposing electron donating effect through a resonance effect [58]. This ambiguous behavior of the fluorine substituent will be further analyzed on the basis of modern valence bond theory.

Figure 2a shows a plot of energy of hydrogenation of alkenes from B3LYP/6-311++G(d,p) level of theory versus delocalization index of the corresponding unsaturated $\mathrm{C}=\mathrm{C}$ bonds from B3LYP electron density; Fig. $2 b$ shows a plot of Wiberg bond index obtained from B3LYP/6-311++G(d,p) level of theory versus delocalization index of the corresponding unsaturated $\mathrm{CC}$ bonds of alkenes and alkynes, fluorosubstituted or not.

The plot in Fig. 2a shows that the stability of the alkenes increases as the DI of the $\mathrm{CC}$ bond decreases. The results presented in Fig. 2a reinforce the idea that alkyl groups stabilize alkenes by removal of electron density of double CC bonds, respectively (when compared to a reference molecule, ethylene). 


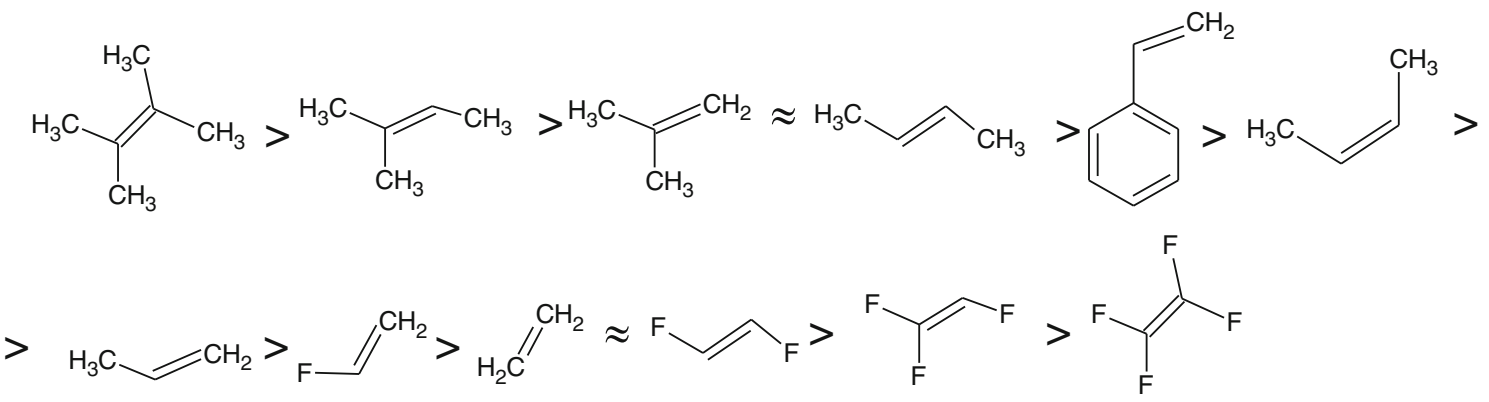

a

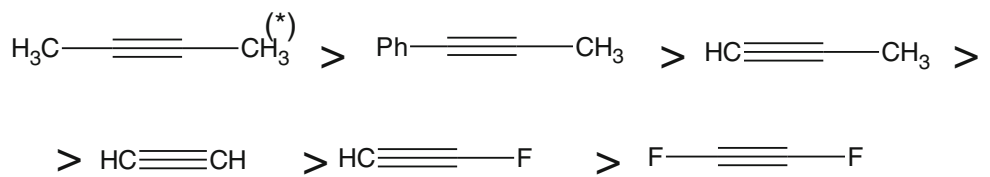

b

Fig. 1 Relative stability of all studied alkenes (a) and alkynes (b) from free energy of hydrogenation calculated by G4 and B3LYP/6-311G++(d,p). *No optimized structure for 2-butyne in G4 calculation

The plot in Fig. 2b shows that the results of Wiberg bond index and DI have an excellent correlation, which reinforces the results found with DI.

Further results and discussion concern the analysis of the ambiguous behavior of the fluorine atom attached to vinyl carbon atoms in substituted alkenes by using modern valence bond theory. As stated above, the generalized valence bond method generates a CASSCF-type wavefunction with univocal VB orbitals, which are closer to the Lewis model of chemical bonding.

Valence orbitals of sigma and $\pi$ bonds are singly occupied in all modern VB methods, which avoid problems of electron correlation and allow the evaluation of orbitals overlap. The orbitals overlap can be associated with the strength of a covalent bond and can also be used to detect orbital delocalization under the influence of vicinal substituents.
Figure 3a shows the doubly occupied VB orbitals of fluorine lone pairs (LP 1, 2 and 3) and singly occupied VB orbitals of C$\mathrm{F}$ bond, named $\mathrm{VB}(\mathrm{C}-\mathrm{F})_{1}$ and $\mathrm{VB}(\mathrm{C}-\mathrm{F})_{2}$, of fluoroethene. Two lone pairs of fluorine are distorted slightly to the vicinal carbon atom. Data of VB orbitals overlap involving LP 1, LP 2, VB(C$\mathrm{F})_{1}$ and $\mathrm{VB}(\mathrm{C}-\mathrm{F})_{2}$ agree with the graphical information of the corresponding VB orbitals (see Table 3 ). All this information indicates that the fluorine atom has an electron donating nature through the resonance effect of its lone pairs.

Figure $3 \mathrm{~b}$ shows the selected GVB orbitals of trifluorethene: two lone pairs of two fluorine atoms bonded to the same vinyl carbon atom and four singly occupied C-F orbitals from the same vinyl carbon atom. Three GVB lone pairs are not distorted, but LP2' has a slight distortion to vinyl carbon atom. The data in Table 4 agrees with the graphical information from Fig. 3b, where only LP2' has a small overlap integral with $\mathrm{VB}(\mathrm{C}-\mathrm{F}){ }^{\prime}{ }_{1}$ and $\mathrm{VB}(\mathrm{C}-\mathrm{F}){ }_{2}$. These information indicate that
Fig. 2 a Plot of free energy of hydrogenation from B3LYP/6$311++\mathrm{G}(\mathrm{d}, \mathrm{p})$ versus $\mathrm{C}=\mathrm{C}$ delocalization index (DI) of substituted alkenes. b Plot of Wiberg bond index from B3LYP/ $6-311++\mathrm{G}(\mathrm{d}, \mathrm{p})$ versus $\mathrm{C}=\mathrm{C}$ and $\mathrm{C} \equiv \mathrm{C}$ DI of substituted alkenes and alkynes, fluoro-substituted or not

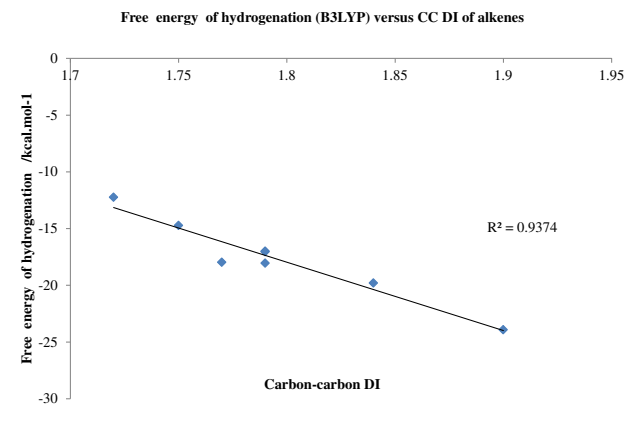

a

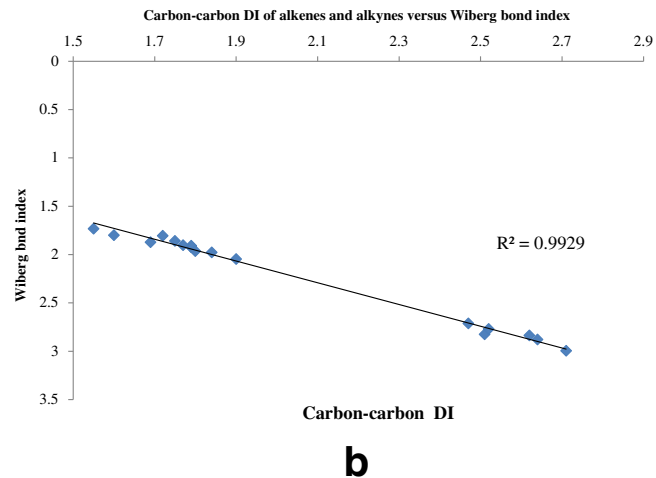



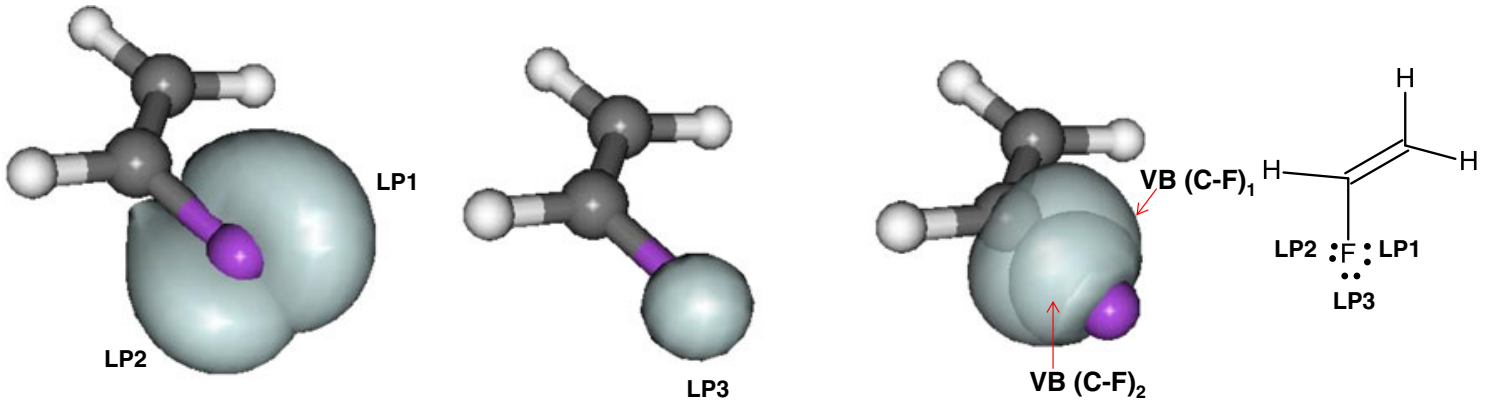

a
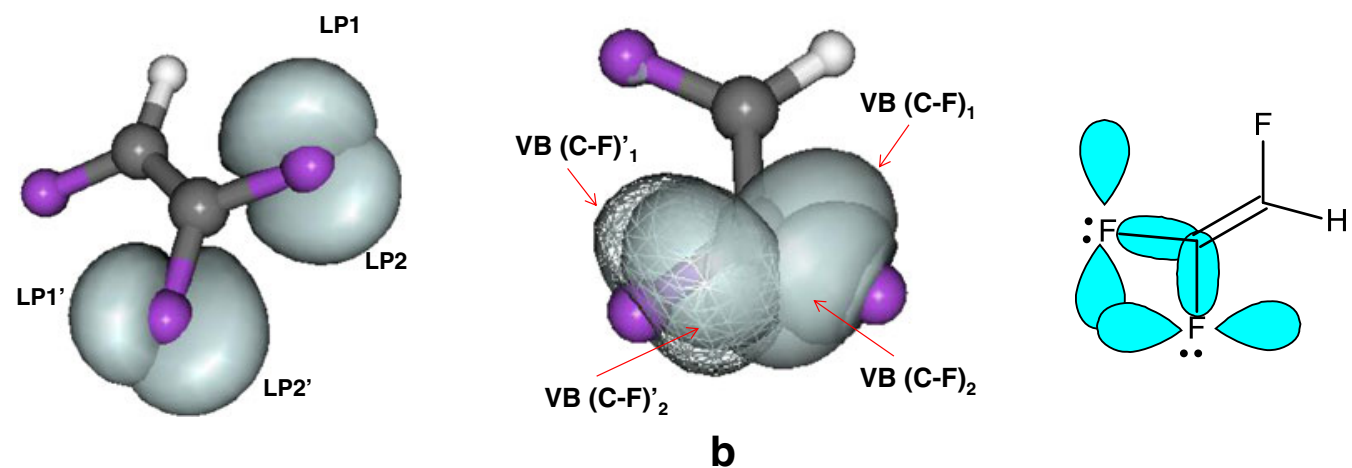

Fig. 3 a Doubly occupied generalized valence bond (GVB) orbitals of lone pairs of fluorine substituent (LP1, LP2 and LP3) and singly occupied GVB orbitals of C-F sigma bond $\left[\mathrm{VB}(\mathrm{C}-\mathrm{F})_{1}\right.$ and $\left.\mathrm{VB}(\mathrm{C}-\mathrm{F})_{2}\right]$ of fluoroethene. b Doubly occupied GVB orbitals of lone pairs of two

fluorine substituents (LP1, LP2, LP1' and LP2') and singly occupied GBV orbitals of two C-F sigma bonds $\left[\mathrm{VB}(\mathrm{C}-\mathrm{F})_{1}, \mathrm{VB}(\mathrm{C}-\mathrm{F})_{2}, \mathrm{VB}(\mathrm{C}-\mathrm{F})^{\prime}{ }_{1}\right.$ and $\mathrm{VB}(\mathrm{C}-\mathrm{F})_{2}$ ] of trifluoroethene

fluorine atoms in trifluoroethene have no electron donating influence from the resonance effect.

Therefore, our GVB study of fluoroethene and trifluoroethene agrees with their topological data and shows that fluorine atom in fluoroethene has a considerable electron donating effect (in which it becomes a slight EWG) while trifluoroethene has no electron donating effect from fluorine (where it becomes a strong EWG).

\section{Conclusions}

The influence of alkyl groups in the order of stability of the studied alkenes derived from the calculation of the free energy of hydrogenation using B3LYP/6-311++G(d,p) level of theory

Table 3 Overlap matrix of selected valence bond (VB) orbitals of fluoroethene of fluorine lone pairs (LP1, LP2 and LP3) and VB orbitals of C-F bond $\left[\mathrm{VB}(\mathrm{C}-\mathrm{F})_{1}\right.$ and $\left.\mathrm{VB}(\mathrm{C}-\mathrm{F})_{2}\right]$

\begin{tabular}{lllll}
\hline & LP1 & LP2 & LP3 & VB (C-F $)_{1}$ \\
\hline VB $(\mathrm{C}-\mathrm{F})_{1}$ & 0.104 & 0.040 & $0^{\mathrm{a}}$ & $1.0^{\mathrm{b}}$ \\
$\mathrm{VB}(\mathrm{C}-\mathrm{F})_{2}$ & 0.064 & 0.039 & 0 & 0.885 \\
\hline
\end{tabular}

${ }^{\text {a }}$ Minimum overlap value

${ }^{\mathrm{b}}$ Maximum overlap value

is similar to that obtained from G4 level of theory; both orders of stability are similar to that in [51]. However, the order of stability between 2-methyl-2-butene and 2,3-dimethyl-2-butene is inaccurate owing to the competition between the stabilizing inductive effect and the destabilizing steric hindrance effect of the alkyl groups attached to the vinyl carbons.

Fluorine atoms attached to unsaturated carbon atoms in substituted alkenes display ambiguous behavior. When two fluorine atoms are attached to the same vinyl carbon atom, they destabilize the corresponding substituted alkene with respect to ethene. Nonetheless, when only one fluorine atom is attached to one or each vinyl carbon atom it imparts a more stable fluoro-substituted alkene, or equally stable 1,2-difluorosubstituted alkene with respect to ethene.

Table 4 Overlap matrix of selected VB orbitals of trifluoroethene of two fluorine lone pairs (LP1, LP2, LP1' and LP2') and of two C-F sigma bonds $\left[\mathrm{VB}(\mathrm{C}-\mathrm{F})_{1}, \mathrm{VB}(\mathrm{C}-\mathrm{F})_{2}, \mathrm{VB}(\mathrm{C}-\mathrm{F}){ }_{1}{ }_{1}\right.$ and $\left.\mathrm{VB}(\mathrm{C}-\mathrm{F}){ }_{2}{ }_{2}\right]$

\begin{tabular}{lllll}
\hline & LP1 & LP2 & LP1 & LP2 \\
\hline $\mathrm{VB}(\mathrm{C}-\mathrm{F})_{1}{ }_{1}$ & $-^{\mathrm{a}}$ & 0 & 0 & 0 \\
$\mathrm{VB}(\mathrm{C}-\mathrm{F})_{2}$ & $-^{\mathrm{a}}$ & 0 & 0 & 0 \\
$\mathrm{VB}(\mathrm{C}-\mathrm{F}){ }_{1}$ & $-^{\mathrm{a}}$ & $-^{\mathrm{a}}$ & 0 & 0.010 \\
$\mathrm{VB}(\mathrm{C}-\mathrm{F}){ }_{2}$ & $-^{\mathrm{a}}$ & $-^{\mathrm{a}}$ & 0 & 0.011 \\
\hline
\end{tabular}

${ }^{\text {a }}$ Negative value has no physical meaning 
Although alkyl groups attached to unsaturated carbon atoms stabilize alkenes and alkynes, they are not electron donating groups for unsaturated hydrocarbons, as indicated in many undergraduate organic chemistry textbooks. In alkenes and alkynes, alkyl groups behave as slight EWGs according to QTAIM and Wiberg bond index results.

EWGs attached to unsaturated carbon atoms of alkenes and alkynes have two different behaviors: slight EWGs stabilize unsaturated carbon atoms while strong EWGs destabilize unsaturated carbon atoms.

Acknowledgments The authors thank Fundação de Amparo à Pesquisa do Estado do Rio Grande do Norte (FAPERN), Coordenação de Aperfeiçoamento de Pessoal de Nível Superior (CAPES), Conselho Nacional de Desenvolvimento Científico e Tecnológico (CNPq) and Agência Nacional de Petróleo - Programa de Recursos Humanos 30 (ANP PRH-30) for financial support.

\section{References}

1. Conn JB, Kistiakowsky GB, Smith EA (1939) Heats of organic reactions. VIII. Some further hydrogenations, including those of some acetylenes. J Am Chem Soc 61:1868-1876

2. Dolliver MA, Gresham TL, Kistiakowsk GB, Smith EA, Vaughan WE (1937) Heats of organic reactions. VI. Heats of hydrogenation of some oxygen-containing compounds. J Am Chem Soc 60:440-450

3. Kistiakownsky GB, Doliver MA, Gresham TL, Vaughan WE (1937) Heats of organic reactions. V. Heats of hydrogenation of various hydrocarbons. J Am Chem Soc 59:831-841

4. Kistiakowsky GB, Romeyn HJ, Ruhoff JR, Smith HA, Vaughan WE (1936) Heats of organic reactions III. Hydrogenation of some higher olefins. J Am Chem Soc 58:137-145

5. Kistiakowsky GB, Ruhoff JR, Smith HA, Vaughan WE (1935) Heats of organic reactions. II. Hydrogenation of some simpler olefinic hydrocarbons. J Am Chem Soc 57:876-882

6. Kistiakowsky GB, Ruhoff JR, Smith HA, Vaughan WE (1936) Heats of organic reactions. IV. Hydrogenation of some dienes and of benzene. J Am Chem Soc 58:146-153

7. Kistiakowsky GB, Romeyn HJ, Ruhoff JR, Smith HA, Vaughan WE (1935) Heats of organic reactions. I. The apparatus and the heat of hydrogenation of ethylene. J Am Chem Soc 57:65-75

8. Williams RB (1942) Heats of catalytic hydrogenation in solution I Apparatus, technique, and the heats of hydrogenation of certain pairs of stereoisomers. J Am Chem Soc 64:1395-1404

9. Turner RB, Meador WR, Winkler RE (1957) Heats of hydrogenation .1. Apparatus and the heats of hydrogenation of bicyclo-[2, 2, 1]heptene, bicyclo[2,2,1]heptadiene, bicyclo[2,2,2]octene and bicyclo[2,2,2]octadiene. J Am Chem Soc 79:4116-4121

10. Rogers DW, McLaffer F (1971) New hydrogen calorimeter-heats of hydrogenation of allyl and vinyl unsaturation adjacent to a ring. Tetrahedron 27:3765-3775

11. Rogers DW, Skanupon S (1974) Heats of hydrogenation of 16 terminal monoolefins-alternating effect. J Phys Chem 78:25692572

12. Frederick DR (1940) Heats of formation of gaseous hydrocarbons. Chem Rev 27:1-16

13. Fuchs R, Peacock LA (1979) Gaseous heats of hydrogenation of some cyclic and open-chain alkenes. J Phys Chem 83:1975-1978

14. Maskill H (1985) The physical basis of organic chemistry. Oxford University, Oxford
15. Solomons TWG, Fryhle CB (2000) Organic chemistry, 7th edn. Wiley, New York

16. Sagadeev EV, Barabanov VP (2006) Calculations of the enthalpies of combustion of organic compounds by the additive scheme. Russ J Phys Chem 80:S152-S162

17. Ibrahim MR, Schleyer PV (1985) Atom equivalents for relating abinitio energies to enthalpies of formation. J Comput Chem 6: $157-167$

18. Dewar MJS, Storch DM (1985) The development and use of quantum molecular-models comparative tests of theoretical procedures for studying chemical-reactions. J Am Chem Soc 107:3898-3902

19. Wiberg KB (1984) Group equivalents for converting abinitio energies to enthalpies of formation. J Comput Chem 5:197-199

20. Kristyan S, Ruzsinszky A, Csonka GI (2001) Reproducing Gaussian3 total energy using fitted atomic correlation parameters for the rapid estimation of correlation energy from partial charges method and Hartree-Fock results. J Phys Chem A 105:1926-1933

21. Kristyan S, Ruzsinszky A, Csonka GI (2001) Accurate thermochemistry from corrected Hartree-Fock results: rapid estimation of nearly experimental quality total energy using the small 6-31G(d) basis set. Theor Chem Acc 106:319-328

22. Kristyan S, Ruzsinszky A, Csonka GI (2001) The performance of the rapid estimation of basis set error and correlation energy from partial charges method on new molecules of the G3/99 test set. Theor Chem Acc 106:404-411

23. Ruzsinszky A, Van Alsenoy C, Csonka GI (2002) Optimal selection of partial charge calculation method for rapid estimation of enthalpies of formation from Hartree-Fock total energy. J Phys Chem A 106: $12139-12150$

24. Cioslowski J, Liu GH, Piskorz P (1998) Computationally inexpensive theoretical thermochemistry. J Phys Chem A 102:9890-9900

25. Cioslowski J, Schimeczek M, Liu G, Stoyanov V (2000) A set of standard enthalpies of formation for benchmarking, calibration, and parametrization of electronic structure methods. J Chem Phys 113: 9377-9389

26. Mandado M, Vila A, Grana AM, Mosquera RA, Cioslowski J (2003) Transferability of energies of atoms in organic molecules. Chem Phys Lett 371:739-743

27. Whyman GE, Savoskin MV, Yaroshenko AP, Kapkan LM, Popov AF (2003) Straightforward ab initio calculation of enthalpies of combustion and formation of hydrocarbons. J Mol Struct Theochem 637:183-187

28. Bruice PY (1998) Organic chemistry, 2nd edn. Prentice Hall, New Jersey

29. McMurry J (1997) Quimica organica, 4th edn. Livros Técnicos e Científicos Editora, Rio de Janeiro

30. Volhardt KPC, Schore NE (2010) Organic chemistry - structure and function, 6 th edn. Freeman, New York

31. Cunha S (2003) Estabilidade relativa de alcenos: análise dos critérios encontrados nos livros textos de graduação e uma proposta de explicação operacional para alcenos dissubstituídos. Quim Nova 26:948-951

32. Whangbo MH, Stewart KR (1982) On the thermodynamic stability and reactivity of alkyl-substituted alkenes. J Org Chem 47:736-738

33. Schleyer PV, Kost D (1988) A comparison of the energies of doublebonds of 2nd-row elements with carbon and silicon. J Am Chem Soc 110:2105-2109

34. Schmidt MW, Truong PN, Gordon MS (1987) Pi bond strengths in the second and third periods. J Am Chem Soc 109:5217

35. Sun H, Hrovat DA, Borden WT (1987) Why are pi-bonds to phosphorus more stable toward addition-reactions than pi-bonds to silicon. J Am Chem Soc 109:5275-5276

36. Young DC (2001) Computational chemistry: a practical guide for applying techniques to real-world problems. Wiley, New York

37. Larry AC, Paul CR, Krishnan R (2007) Gaussian-4 theory. J Chem Phys 126:084108 
38. Li J, McWeeny R (2002) VB2000: pushing valence bond theory to new limits. Int J Quantum Chem 89:208-216

39. Li X, Frisch MJ (2006) Energy-represented direct inversion in the iterative subspace within a hybrid geometry optimization method. J Chem Theory Comput 2:835-839

40. Pulay P, Fogarasi G (1992) Geometry optimization in redundant internal coordinates. J Chem Phys 96:2856

41. Becke AD (1993) Density-functional thermochemistry. 3. The role of exact exchange. J Chem Phys 98:5648-5652

42. Lee C, Yang W, Parr RG (1988) Development of the Colle-Salvetti correlation-energy formula into a functional of the electron density. Phys Rev B 37:785

43. Frisch GWT MJ, Schlegel HB, Scuseria GE, Robb MA, Cheeseman JR, Scalmani G, Barone V, Mennucci B, Petersson GA, Nakatsuji H, Caricato M, Li X, Hratchian HP, Izmaylov AF, Bloino J, Zheng G, Sonnenberg JL, Hada M, Ehara M, Toyota K, Fukuda R, Hasegawa J, Ishida M, Nakajima T, Honda Y, Kitao O, Nakai H, Vreven T, Montgomery JA Jr, Peralta JE, Ogliaro F, Bearpark M, Heyd JJ, Brothers E, Kudin KN, Staroverov VN, Kobayashi R, Normand J, Raghavachari K, Rendell A, Burant JC, Iyengar SS, Tomasi J, Cossi M, Rega N, Millam JM, Klene M, Knox JE, Cross JB, Bakken V, Adamo C, Jaramillo J, Gomperts R, Stratmann RE, Yazyev O, Austin AJ, Cammi R, Pomelli C, Ochterski JW, Martin RL, Morokuma K, Zakrzewski VG, Voth GA, Salvador P, Dannenberg JJ, Dapprich S, Daniels AD, Farkas Ö, Foresman JB, Ortiz JV, Cioslowski J, Fox DJ (2009) Gaussian 09. Revision A.01. Wallingford

44. Biegler-König F, Schönbohm J (2002) Update of the AIM2000program for atoms in molecules. J Comput Chem 23(15):1489-1494

45. Biegler-Konig F, Schonbohm J, Bayles D (2001) Software news and updates. AIM2000 - a program to analyze and visualize atoms in molecules. J Comp Chem 22:59

46. Bader RFW (1994) Atoms in molecules a quantum theory. Oxford University Press, New York
47. Wang Y-G, Matta CF, Werstiuk NH (2003) Comparison of localization and delocalization indices obtained with hartree-fock and conventional correlated methods: effect of coulomb correlation. J Comp Chem 24:1720-1729

48. Ängyá JG, Loos M, Mayer I (1994) Covalent bond orders and atomic valence indices in the topological theory of atoms in molecules. $\mathrm{J}$ Phys Chem 98:5244-5248

49. Fradera X, Austen MA, Bader RFW (1999) The Lewis model and beyond. J Phys Chem A 103:304-314

50. Solà M, Mestres J, Carbó R, Duran M (1996) A comparative analysis by means of quantum molecular similarity measures of density distributions derived from conventional ab initio and density functional methods. Chem Phys 104:636-647

51. Jordi Poater MD, Solà M, Silvi B (2005) Theoretical evaluation of electron delocalization in aromatic molecules by means of Atoms in Molecules (AIM) and Electron Localization Function (ELF) Topological Approaches. Chem Rev 105:3921

52. Firme CL, Antunes OAC, Esteves PM (2009) Relation between bond order and delocalization index of QTAIM. Chem Phys Lett 468:33

53. Wiberg KB (1968) Application of the pople-santry-segal CNDO method to the cyclopropylcarbinyl and cyclobutyl cation and to bicyclobutane. Tetrahedron 24:1083-1096

54. Li J, Duke B, McWeeny R (2009) VB2000. SciNet Technologies, San Diego

55. Varetto U (2009) Molekel 5.4.0.8, Swiss National Supercomputing Center, Manno, Switzerland

56. Goddard WA, Dunning TH, Hunt WJ, Hay P (1973) Generalized Valence bond description of bonding in low-lying states of molecules. Acc Chem Res 6:368-376

57. Allinger NL, Cava MP, Jongh DC, Jonhson CR, Lebel NA, Stevens CL (1978) Química orgânica. Guanabara Dois, Rio de Jameiro

58. Hansch C, Leo A, Taft RW (1991) A survey of Hammett substituent constants and resonance and field parameters. Chem Rev 91:165-195 